\title{
Ecology of knowledge's and internet: rethinking research about teaching and learning
}

\begin{abstract}
In view of the growing interest of researches that deal specifically with teaching and learning in empirical contexts and the use of digital information and communication technologies to understand practices, conditions and impacts of Internet use in education, this article aims at discussing the academic production process, in particular the one related to teaching and learning contexts. To do so, one seeks as theoretical-methodological route to develop a qualitative epistemological discussion about knowledge(s), by organizing it based on the Foucauldian concepts of savoir and connaissance, on the plural conception of epistemology and on the notion of critical literacy, so as to (re)think the own knowledge construction process from the perspective of an ecology of knowledge's. One considers that this perspective allows us to rethink research based on two founding points: the first one is its qualitative character, since qualitative researches seek to describe and to understand the practices of the participants involved in any investigation; and secondly, its socio-political character, since empirical researches in teaching and learning contexts through the Internet might contribute to the development of both basic and higher education.
\end{abstract}

Volume 2 Issue 3 - 2017

\author{
Petrilson Pinheiro \\ Professor of the Institute of Language Studies, University of \\ Campinas, Brazil
}

Correspondence: Petrilson Pinheiro, Professor of the Institute of Language Studies, University of Campinas, Brazil, Email petrilson@iel.unicamp.br

Received: October 13, 2017 | Published: December 12, 2017

Keywords: epistemologies, ecology of knowledge's, internet, school, literacy's

\section{Introduction}

There has been a growing interest of quantitative and qualitative researches in the humanities and social sciences in understanding practices, conditions and impacts of Internet use in education, specifically through teaching and learning empirical contexts and the use of information and communication technologies (ICT). Be it to observe and analyze challenges in implementing and developing digital literacy's projects, be it to show practices that somehow have already been well succeeded, with or without academic intervention, empirical researches carried out by universities and research centers have been a relatively important impact on basic education.

However, it is needed to highlight that if, on the one hand, the academic world has made efforts to "improve'2 teaching and learning practices and conditions in diverse basic education contexts, by means of the production of a certain type of scientific knowledge, on the other hand, it is also needed to know how such knowledge produced by academy indeed reaches the social actors who should be directly involved and affected, namely, school teachers and students. In this sense, it possible to make the following question: How many works produced in the academy (journal articles, thesis, dissertations) are in fact shared with the research subjects and not limited to being used for academic purposes (events and books and/ or academic journals publications)?

One possible answer for that question will be given throughout this article, in which the research production process will be discussed, particularly the one related to teaching and learning contexts. To

${ }^{1}$ This article discussion does not include several documental researches (analysis of official education documents and teaching materials; for example), which, as well as many empirical researches, have much contributed to rethink basic education practices and curricula.

${ }^{2}$ The verb "improve" is used between commas because it's meaning is always relative, inasmuch as it depends on who benefits from it, and in which context(s) it happens. do so, firstly, one seeks as a theoretical-methodological route to develop a qualitative epistemological discussion about knowledge(s), by organizing it based on the Foucauldian concepts of savoir and connaissance; then, one relates these concepts to the plural conception of epistemology and critical literacy, by taking a concrete example of how to deal with the information that circulates on the Internet (the free online encyclopedia Wikipedia), in order to (re)think the knowledge construction process from the perspective of an ecology of knowledge's. Lastly, one considers that this perspective allows us to deal with research in teaching and learning based on two founding points: the first one is its qualitative character, since qualitative researches seek to describe and to understand the practices of the participants involved in any investigation; and secondly, its sociopolitical character, since empirical researches in teaching and learning contexts by means of Internet can contribute to the development of both basic and higher education.

\section{Epistemologies for an ecology of knowledge's}

The singular conception of 'epistemology', as theory of knowledge, deals basically with understanding what 'knowledge' covers. In this perspective, the first issue to be raised is the acknowledgment that the verb 'know' presents both a propositional meaning - for discovering meaning based upon propositions (premises and value judgments formed by truth values (true or false)) and a procedural meaning a practical and performative issue for knowing how to accomplish something in order to achieve some end or goal.

Although both meanings are relevant for understanding knowledge more broadly, only the first one (propositional meaning) is privileged in the traditional philosophical epistemology. However, it is necessary to problematize the own conception of epistemology in order to deal with the multiplicity and interrelationship of knowledge's embedded particularly in the research act itself, or in social life, in general. A possible way to develop this problem-solving issue is to 
take the Foucauldian distinction between savoir and connaissance. ${ }^{3}$ According to Foucault, ${ }^{1}$ knowledge (savoir) is that of which one can speak in a discursive practice and which is specified by that fact: the domain constituted by the different objects that will or will not acquire a scientific status; knowledge is also the space in which the subject may take up a position and speak of the objects with which he deals in his discourse; knowledge is also the field of coordination and subordination of statements in which concepts appear and are defined, applied and transformed; There are bodies of knowledge that are independent of the sciences (which are neither their historical prototypes, nor their practical by-products), but there is no knowledge without a particular discursive practice; and any discursive practice may be defined by the knowledge that it forms.

Therefore, for the author, savoir would be related to knowledge's processes that are constituted in not-fixed discursive practices, inasmuch as they are always in constant change due to modifications to which they are submitted in these own knowledge's processes. Connaissance, on the other hand, would correspond to the constitution of discourses responsible for the construction of a complex process of rationalization, identification and classification of objects. In this sense, knowledge is understood as relatively rigid and stagnant. ${ }^{1}$

Within this complex vision of knowledge, differently from connaissance, savoir is not founded in a scientific principle, since it is not needed to be the result or product of a reliable research method. Therefore, a savoir is not rated as 'genuine' or not, based on scientific principles modes of knowledge related to highly developed apparatuses to justify or prove something (e.g. to be considered as true or false), but through multiple experiences which constitutes social practices, of which science is only a part (in several contexts, it is a minimum or even an inexistent part). By proposing Archaeology of knowledge, Foucault precisely focuses on the concept of savoir, by exploring the axis practice/knowledge (savoir)/science. In this sense, the author points out that whereas the history of ideas finds the point of "balance of its analysis in the element of connaissance (and is thus forced, against its will, to encounter the transcendental interrogation), archaeology finds the point of balance of its analysis in savoir - that is, in a domain in which the subject is necessarily situated and dependent and can never figure as titular". ${ }^{1}$

One infers that, for Foucault, the Archaeology of knowledge is not constituted as a domain of known things, but of things to be known, whose rigor varies according to the contexts in which they are forged. In this sense, savoir, the prototypical element of the Archaeology, is not properly based upon "the system of postulates that governs all the branches of knowledge (connaissances) $;{ }^{1}$ it is produced through many divisions and subdivision, a 'constellation' of (other) saviors that constitutes "Archaeological territories", which present a bundle of relations that may "extend to 'literary' or 'philosophical' texts, as well as scientific ones. Knowledge is to be found not only in demonstrations, it can also be found in fiction, reflexion, narrative accounts, institutional regulations and political decisions. ${ }^{1}$

3The English word 'knowledge' is used to represent both French words connaissance and savoir. Connaissance refers here to a particular corpus of knowledge. Savoir is usually defined as knowledge in general, the totality of connaissance. Although the concepts of savoir e connaissance present a certain inconsistency along the works of Foucault, especially in Archeology of Knowledge, the conceptual differentiation is considered pertinent for the epistemological discussion proposed in this paper. For a more in-depth discussion on this issue, see FABION JD (1998) Essential Works of Foucault. Vol II Aesthetics, Method and Epistemology, The New Press, USA.
This vision of Archaeology is particularly relevant for this article in order to understand and think about the own concept of "episteme". For Foucault, episteme is as an indefinite field of relations, which is formed by connections between discursive practices and sciences, always permeated by power relations. This is what makes possible, according to the author, the existence of "epistemological figures", a set of relations that may be connected with the idea of knowledge, in Sousa Santos ${ }^{2}$ as a corollary of social practices, which challenges knowledge as connaissance. To this respect, the author asserts that "conceptions of knowledge, of what it mean to know, of what counts as knowledge and how that knowledge is produced are as diverse as the cosmologies and normative frameworks. All social practices involve knowledge. The production of knowledge is, in itself, a social practice and what distinguishes it from other social practices is its self-reflexivity, which productively reshapes the context of practices in motive and engine of actions. ${ }^{2}$

Based on a plural conception of knowledge, which arises from social practices and not form knowledge in abstracto, Sousa Santos develops the plural noun "epistemologies" instead of "epistemology" ${ }^{4}$ The author points out two premises to deal with what he calls "epistemologies of the South": First, the understanding of the world is much broader than the Western understanding of the world. This means that the progressive transformation of the world may also occur in ways not foreseen by Western thinking, including critical Western thinking. Second, the diversity of the world is infinite. It is a diversity that encompasses very distinct modes of being, thinking and feeling; ways of conceiving of time and the relations among human beings and between humans and non-humans, ways of facing the past and the future and of collectively organising life, the production of goods and services, as well as leisure.

According to Sousa Santos, science, including the social sciences are part of the project of Western modernity, then, he states that the sciences are much more part of the problem than part of the solution. In this sense, science, at the most, may help us to elucidate and bring analytical precision to the different dimensions of our problem. One reasonable possibility to go beyond Western Science's theoretical view of the world, or in Foucault's terms, a diversity of savoir to promote an archaeology of knowledge, is to problematize the own relationship between theory and practice. This seems to be in line with vision of Deleuze, who, in a conversation with Michel Foucault, points that: Possibly we're in the process of experiencing a new relationship between theory and practice. At one time, practice was considered an application of theory, a consequence; at other times, it bad an opposite sense and it was thought to inspire theory, to be indispensable for the creation of future theoretical forms. In any event, their relationship was understood in terms of a process of totalization. For us, however the question is seen in a different light. The relationships between theory and practice are far more partial and fragmentary. On one side,

${ }^{4}$ Sousa Santos' criticism of the singular concept of "epistemology" arises out of the fact that the theories and concepts developed in the global North and employed in the entire academic world do not "identify all the immensity of alternatives of life, conviviality and interaction with the world. When they do, they do not valorise them as being valid contributions towards constructing a better society. The epistemologies of the South do not address the idea of what we consider relevant knowledge perse, because they are concerned with things, ways of knowing, that very often do not count as knowledge. They are viewed as superstitions, opinions, subjectivities, common sense. They are not rigorous, they are not monumental and therefore they are discounted. As a consequence, the epistemologies of the South have to occupy the term 'epistemology' in order to re-signify it". ${ }^{2}$ 
a theory is always local and related to a limited field and it is applied in another sphere, more or less distant from it. The relationship which holds in the application of a theory is never one of resemblance. Moreover, from the moment a theory moves into its proper domain, it begins to encounter obstacles, walls and blockages which require its relay by another type of discourse (it is through this other discourse that it eventually passes to a different domain). Practice is a set of relays from one theoretical point to another and theory is a relay from one practice to another. No theory can develop without eventually encountering a wall and practice is necessary for piercing this wall. ${ }^{3}$

The possibility to "pierce" the wall of theory is, of course, related to the researchers' (science as a whole) willingness to see and deal with life social practices. This could turn the practice into the "own stage of creation of theoretical reflections, namely, theory and practice are not different things. Theory is relevant for practice because it is conceived inside practice". From this perspective, to understand the relationship between theory and practice as constitutive of a research process and not as watertight categories, can promote more than a new look on a given object of research; it can construct a new research object, since, inevitably, it leads us to (re) formulate new research questions and new objectives, which, in turn, lead us to review and even innovate theoretical paths and methods of data analysis. However, it is important to emphasize that innovations in the construction of research objects are not only dependent on methodological or theoretical choices, as if the options of "doing research" should be teleological oriented by or to a particular method or theory. It is therefore a matter of discussing the very notion of "epistemology"; not the one that has historically concealed from its constitution and reflection social, cultural and political contexts of (re) production of knowledge, but the one (notion) that seeks to rethink them based on different social relations and practices.

In order to understand knowledge construction in a broader and more complex way, especially in the very act of doing research, it is therefore necessary to promote heterarchical dialogues between knowledge's (savoirs) by valuing even those who historically have been neglected from the formation process of modern scientific knowledge. According to Sousa Santos, ${ }^{2}$ these heterarchical dialogues are the basis of "ecology of knowledge". For the author, the idea of ecology of knowledge is an invitation to the promotion of nonrelativistic dialogues among knowledge's, granting "equality of opportunities" to the different kinds of knowledge engaged in ever broader epistemological disputes aimed both at maximizing their respective contributions to build a more democratic and just society and at decolonizing knowledge and power.

Sousa Santos ${ }^{2}$ emphasizes that the ecology of knowledge's perspective, by bringing together different kinds of knowledge's, confronts the monoculture logic of scientific knowledge and rigor by identifying and promoting interaction and a new dynamics of a plurality of heterogeneous knowledge's, as well as criteria of rigor and validity that operate credibly in social practices. In this respect, it is precisely by seeking to acknowledge and to know the epistemological diversity that exists in the world, far beyond scientific knowledge, that the idea of searching a general epistemology would be not only counterproductive, but above all incomplete and insufficient to deal with knowledge formation and validation.

However, even being relational and plural, the ecology of knowledge's does not presuppose that the dialogues between different knowledge's are heterarchical; indeed there is always hierarchy between knowledge's, but it is constructed through production of concrete knowledge's in situated contexts. In this sense, Sousa Santos ${ }^{2}$ points out that ecology of knowledge's are based on the pragmatic idea that it is "necessary to reassess the concrete interventions in society and in nature that the different knowledge's can offer. It focuses on the relations between knowledge's and on the hierarchies that are generated between them, since no concrete practice would be possible without such hierarchies. However, rather than subscribing to a single, universal and abstract hierarchy among knowledge's, the ecology of knowledge's favours context dependent hierarchies, in light of the concrete outcomes intended or achieved by different knowledge practices. Concrete hierarchies emerge from the relative value of alternative real-world interventions". In this sense, complementarity or contradictions may exist between the different types of intervention when one deals with real and concrete practices of knowledge's, where there can always be complementarity and clashes between different knowledge's (savoirs and connaissance), it becomes evident the need to pluralize the word "epistemology", as Signorinit does, when questions the reason(s) of speaking about epistemologies and not about methods or models. She asserts that such an issue "is of interest for applied field researches since it is related to meta reflexivity, which is increasingly necessary and urgent: what kind of knowledge is being produced with and about language? How? Based on what? For the benefit (or damage) of whom?

These questions raised by Signorini lead us to ask for the very nature of (re) production of knowledge, since they allow us to glimpse the possibility of situating and historicizing any object of investigation as well as to throw a critical eye on it which eventually enables a transformation of the object itself. One possible way of promoting such a transformation is to deal with this plural relational notion of knowledge ("epistemologies") in teaching and learning empirical researches of through the use of ICT. This might not only produce technological or methodological changes in schooling literacy practices, but, in fact, create ecology of knowledge's environment in education, which will be discussed in the next section.

\section{Ecology of knowledge's and ICT: rethinking research in teaching and learning contexts}

In order to establish a relationship between the theoretical discussion accomplished so far and teaching-learning research, the following question can be raised: how empirical research, of practicaltheoretical nature, could contribute to explore and promote the use of ICT, in a Web 2.0 environment, which enables students and teachers to become producers, diffusers and consumers of texts?

The ICT, acronym for Information and communications technology, is most used to refer to the integration and convergence of telecommunications, which has become widespread worldwide with the advent of the Internet. Indeed, the ICT have heavily impacted the social and cultural life of our societies and, particularly have enabled new literacy's that have been increasingly distant from typographic literacy practices. In the era of Big Data, in which data sets are so large and complex and of The Internet of Things, in which such data are collected, changed and exchanged by means of huge and complex networks of physical objects of all sorts, the (traditional) way one deals with information, communication and, by extension, literacy must be reviewed. 
Within such a context of transinformation, ${ }^{5}$ a special attention shall be paid to Web 2.0, term used by O'Reilly (2005) to refer to the user-generated content of the second generation of World Wide Web, namely, users are not anymore limited to a passive viewing of content; they can continuously interact and collaborate with each other in multilayered and dynamic social media dialogues. In this sense, Web 2.0 enables new techniques and socio-cultural conditions for the expansion of communicative practices in the digital world, in which people not only receive, but also publish information on the Internet, which has challenged the very traditional categories of author and reader.

Indeed, Web 2.0 has strongly contributed for social, cultural and technological changes worldwide. However, schooling system, conversely, seems to be resistant to changes, since they by and large deal with graphocentric practices that do not reflect these changes. Therefore, the schooling system needs be rethought and re-evaluated (its functionality, strategies and practices), in order to try to deal with the multifarious demands of the digital age, which reorganizes itself each time more dynamic and complex and which redefines new institutional roles increasingly interrelated with the uses of ICT that emerge in the current scenario of a globalized world.

In studies carried out in the last few years together with some (master and $\mathrm{PhD}$ ) graduate students, ${ }^{5-9}$ we have realized that the issue of ICT use in schools goes much beyond the technology access. There is still, however, a huge gap, in general, between practices of Brazilian and the daily lives of many students, due to the fact that so many schools have stopped in time and have not been able to keep up with the constant changes imposed by scientific and technological development. This in itself would be a more than enough justification for the use of ICT at Brazilian schools, which, in general, are still in the "pre-virtual era". 6

Nevertheless, the installation of computer labs, equipped with Internet and sophisticated programs, is not enough to make students literate in today's increasingly hyper-semioticized society, in as much as, besides material investment, it is necessary above all human investment. Thus, in this scenario, one must consider that the simple introduction of new ICT into schools is not able to guarantee a successful work. In other words, that doesn't mean that ICT will on its own automatically create innovation and new spaces for learning. "The potential of digital media can only be realized if it is anchored in a pedagogical, social and organizational context, supported by political commitment. That is why it takes time to realize the learning benefits of ICT in school development projects. Utilization of ICT in central learning activities depends on the school facilitating the use of ICT in a comprehensive way (ITU, 2006). This means clearly defined pedagogical targets, professional ICT infrastructure, school leadership, organizational development and competence building. ${ }^{10}$

This political commitment to which Søby ${ }^{10}$ refers is what, in other words, makes the simple use of new technologies in a literacy

${ }^{5}$ One calls "transinformation" the current socio-historical moment, in which information not only circulates globally (on World Wide Web), but also suffers metamorphoses to become increasingly fluid and multifaceted in a continuous feedback process that transforms itself.

6The word "virtual" is applied here in the sense given by Levy'12 as "potency", i.e., as something potentially actual, or possible to be accomplished. To refer to the Brazilian schools as institutions that, in general, are in "pre-virtual" era, I mean that, most of them have not yet seen means to make possible the effective use of digital technologies at schools. practice does not constitute as a new literacy, since it is possible to use new ICT for simply replicate longstanding literacy practices. In this regard, Knobel \& Lankshear ${ }^{11}$ show that: We think that what is central to new literacy's is not the fact that we can now "look up information online or write essays using a word processor rather than a pen or typewriter, or even that we can mix music with sophisticated software that works on run-of-the-mill computers but, rather, that they mobilize very different kinds of values and priorities and sensibilities than the literacy's we are familiar with. The significance of the new technical stuff has mainly to do with how it enables people to build and participate in literacy practices that involve different kinds of values, sensibilities, norms and procedures and so on from those that characterize conventional literacy's.

Thus, for the authors, in addition to experiencing the emergence of new digital devices (new technical stuff), it is also necessary a broad conceptual review (new ethos stuff), i.e., new concepts, values, attitudes and sensibilities, so as to think of a new literacy. In this sense, one shall understand that the transformation of social, political and cultural is also the corollary of globalization processes, including the ubiquity of ICT. However, if this ratio is made too directly, without considering the nuances that constitute these processes, we run the risk of being guided by a perspective that fits exclusively on the dynamics of capitalist restructuring, which is consolidated in the current neoliberal model. Such a perspective can lead to the creation of educational models embedded in the marketing logics, suggested and, in some cases, imposed by large conglomerates and international corporations. In the marketing logics, practices of competitiveness, productivity and utilitarianism, which form the basis of the neoliberal discourse, can ultimately transform education into commodities of the globalized world, whose role might be more steered and dimensioned according to their utility and function. ${ }^{12}$

One way of thinking about the use of ICT in schools, which tries to remove the market "aura" from education, would be to understand school literacy's as social practices, i.e., as diverse and multiple, not only the ones legitimized by school. This, in turn, would enable to see school literacy's as "utopia of inter knowledge", ${ }^{2}$ which consists of learning new and less "familiar knowledge's without necessarily having to forget the old ones and one's own. Such is the idea of prudence underlying the ecology of knowledge's. The ecology of knowledge's assumes that all relational practices involving human beings and human beings and nature entail more than one kind of knowledge". ${ }^{2}$ Therefore, to understand literacy's practices as embedded in an ecology of imposes us a challenge of self-reflection as researchers who investigate school contexts: how can we propose "innovative" teaching researches, methods and practices that seek to question the reproduction of school knowledge if, in the academy, we deal with a monopolistic knowledge that does not allow us to interrelate with other knowledge's or communicate beyond university walls?

The proposal of this article to deal with ecology of knowledge's in teaching and learning through the Internet can give us a promising answer to such a question insofar as some of the issues that concern production, diffusion and consumption of information today require us to rethink our own status as (re)producers of knowledge's. This point, in turn, prompts us to make another question: what does it mean to be literate today? Indeed, it is necessary to understand that, on one hand, people are increasingly in symbiosis with the ICT, especially the digital natives ${ }^{13}$ whom by and large deal much more easily with 
the Internet than an adult. However, on the on the hand, youngsters lack a critical eye on the use of what they read, produce and spread on the Internet. In other words, much more than looking for information on the network - something many youngsters seem to do very well today - it is necessary to educate them for critical analysis of the information with which they deal.

In this respect, as the Internet is an open and public environment, to be a "critical literate" is more than ever related to the fact that cyberspace can be useful both for releasing relevant or dubious information (both from the conceptual and ideological point of view). What differs a simple user from a critical literate is that the former is only interested in searching for information in the network, while the latter, on the other hand, is also concerned with the analysis and evaluation of the information sources made available in the digital world. A critical literate is, therefore, a subject that not only recognizes and transits through different online spaces, but seeks to understand the different mechanisms that govern the production, reproduction and diffusion of what circulates on the Internet

One interesting example is Wikipedia. The fact of being ephemeral and multifaceted turns the world's most accessible encyclopaedia into an environment, in principle, not only of consumption, but of "distrust". This is different from off-line printed standard encyclopaedias, taken as documents of "unquestionable truth". Until the end of twenty Century (even nowadays), who (teachers) would dare to question, for instance, one or more entries of Britannica Encyclopaedia (either printed or online versions)? Nowadays, conversely, we can not only have access to a wide variety of online content, but above all we can produce, publish and republish information. Wikipedia is one of the emblematic examples of this new web phase whose production process of entries, unlike Britannica Encyclopaedia, is controlled by the own Internet users. That can therefore lead many people, particularly teachers, to distrust the content produced by Wikipedia.

However, such lack of trust towards Wikipedia could only make sense in the logic of reproduction and acquisition of the monopolistic knowledge aforementioned. From the perspective of the ecology of knowledge, however, this would be out of the question, inasmuch as the ephemeral and multifaceted character of collective intelligence that underlies this perspective is precisely what enables the collaborative writing process of Wikipedia.

Thus, instead of simply distrusting Wikipedia, it might be much better to explore quite relevant issues, such as interfaces between graphocentric school literacy and hypermedia literacy's and information searching and circulating processes on the Internet (choice and filtering of online content, understanding of search results and critical evaluation of the sources found, in which specific issues, such as plagiarism and ethics might be explored in teaching and learning contexts).

In this sense, the idea of the ecology of knowledge seems to be quite adequate to understand the nature and modus operandi of Wikipedia, since it impels us to go beyond unreasonable consumption or rejection (by "distrust"); it enables us to discuss and analyze its content critically. In other words, we are experiencing a (new) era in which, in order to be (digital) "literate", it is not enough to acknowledge and consume contents that circulate on the Internet, but also to understand and evaluate the different mechanisms that governs production, reproduction and dissemination of these contents.
An interesting and promising way to deal with the idea of digital literacy's is to adopt a critical stance in relation to patterns, judgments and actions that constitute literacy's practices. This stance plays a key role in the process of emancipation and formation of critical teachers and students. Some authors ${ }^{14,15}$ propose a critical literacy perspective, strongly influenced by the critical social theory of Paulo Freire, ${ }^{16}$ whose goal is to consider literacy's as socio-discursive practices that enable a critical understanding and questioning of ideological forces and constructs so as to empower and transform individuals. Thus, the concept of critical literacy's is based upon the idea that representations are always ideological, both influencing and constituting social practices and that students should be aware of such representations so as to learn to position themselves critically about them. ${ }^{15}$ In this sense, being literate means being critical. That opens a possibility not to be "merely in the world, but with the world or with others", in which "the individual is not a spectator", but a "re-creator". ${ }^{16}$

The critical literacy's perspective seems to be in line with the idea of ecology of knowledge, which constitutes and is consistent with an epistemologically diverse world, according Sousa Santos. ${ }^{2}$ In this sense, the idea of diversity could be explored in a critical literacy's view as part of an understanding of a broader project of education transformation - the empowerment of diverse knowledge communities and knowledge systems something much beyond the (current) hegemony of West / neo- liberalist knowledge systems. However, in order to contemplate this diversity that underlies the notion of the ecology of knowledge, it is crucial that in our researches we base ourselves on criteria that no longer can be avoided:

a. Situationality and historicity, since researches do not occur in a socio-cultural vacuum. We must situate and discuss them in the light of a social, cultural and historical context

b. Criticality, since all researches elicit from the researcher a critical perspective, above all in relation to research subjects and their social practices (what they think, feel, desire, study, do for a living, for fun etc.), in which power relations always pervade.

From this perspective, we can thus think of research not as a monolithic space of knowledge, but, on the contrary, as an episteme which according to Foucault: ${ }^{1}$ Opens up an inexhaustible field and can never be closed; its aim is not to reconstitute the system of postulates that governs all the branches of knowledge (connaissances) of a given period, but to cover an indefinite field of relations. Moreover, the episteme is not a motionless figure that appeared one day with the mission of effacing all that preceded it: it is a constantly moving set of articulations, shifts and coincidences that are established, only to give rise to others. As a set of relations between sciences, epistemological figures, positivities and discursive practices, the episteme makes it possible to grasp the set of constraints and limitations which, at a given moment, are imposed on discourse: but this limitation is not the negative limitation that opposes knowledge (connaissance) to ignorance, reasoning to imagination, armed experience to fidelity to appearances and fantasy to inferences and deductions; the episteme is not what may be known at a given period, due account taken of inadequate techniques, mental attitudes, or the limitations imposed by tradition; it is what, in the positivity of discursive practices, makes possible the existence of epistemological figures and sciences. 


\section{Conclusion}

Based on the Foucauldian notions of episteme and savoir, which align with the Sousa Santos's plural idea of epistemologies and the concept of critical literacy, one sought to develop a qualitative epistemological meta discussion about knowledge(s) from the perspective of an ecology of knowledge's. Such a complex theoretical-methodological route enables us, researchers, to rethink the knowledge construction process in the very act of doing research in teaching and learning contexts under two founding points: the first one is its qualitative nature. In this sense, the criteria aforementioned (situationality, historicity and criticality) could only be fulfilled through qualitative research, in which the research subjects' life worlds are described, analyzed and understood by taking into consideration their voices and perspectives. Yet, it must not be done only for the sake of researcher's register and subsequent interpretation; the subjects' voices and the values are part of the fabric of the research process itself. Thus, unlike quantitative researches related to language and education, which by and large deal with data collected in schools from a statistical point of view, qualitative researches seek to bring to light the specific contexts of the participants' performances and identities, in which their values, expectations, yearnings, doubts and difficulties are valued. A qualitative look on research, likewise, does not make us forget that the relations between theory and practice are not watertight elements; they are constitutive parts of a complex research process that makes it possible to construct a new research object, since the research course, continuously marked by conflicts between theory and practice, can otherwise lead us to review and even innovate our way of doing research.

The second founding point, deriving from the first, but not reducible to it, is its socio-educational and socio-political nature. The accomplishment of empirical research in teaching and learning contexts through the use of ICT can contribute to the development of education as a whole, both basic and higher education, by means of a more symbiotic relationship between teaching and research. This possibility might be the answer to the question raised at the outset of this article: how many woks produced in the academy (journal articles, thesis and dissertations) are in fact shared with the research subjects and not limited to being used for academic purposes (events and publications in books and/or academic journals)?

The question raised is not just a criticism levelled at on academic world and its researchers (including the author of this article; it is also a criticism levelled at the underpinning productivity logic that impels us more and more to produce, produce and produce, not necessarily concerned about the quality of what is produced. ${ }^{7}$ One possible socio-political way out can be to begin to think the process of academic production itself within another logic - a la Slow Science? ${ }^{8}$ However, this slow-motion logic would not be restricted only to the idea of producing more slowly or in smaller quantity, but to a whole modus operandi that involves the theoretical discussion accomplished towards an ecology of knowledge's, namely, not only from the

${ }^{7}$ It is worthwhile to notice a whole bunch of online journals that have appeared in the last years, many of which, far from the noble desire to promote the quality of academic research, are created only to take money from researchers. ${ }^{8}$ The Slow Science movement, started by German scientists in 2010, with thousands of signatories all over the world, is built around the idea that "Science needs time to think. Science needs time to read, and time to fail. Science does not always know what it might be at right now. Science develops unsteadily, with jerky moves and unpredictable leaps forward at the same time, however, it creeps about on a very slow time scale, for which there must be room and to which justice must be done". See http://slow-science.org/ perspective of production of connaissance, but of a true "utopia of inter knowledge" (the plural perspective of epistemologies), which can recognize and deal with the diversity of knowledge's (savoirs) and at the same time can be less productivity (and therefore more productive), more human and consequently, more ethical. ${ }^{17-19}$

\section{Acknowledgements}

I am grateful to São Paulo Research Foundation for granting the postdoctoral research fellowship in which this article is included (Grant number: 2016/19123-3).

\section{Conflict of interest}

Author declares there is no conflict of interest.

\section{References}

1. Foucault M. The Archaeology of Knowledge. Pantheon Books, New York, USA; 1972. p. 153.

2. Sousa SB. Epistemologies of the South: justice against epistemicide. Routledge, London; 2016.

3. Foucault M, Deleuze G. Intellectuals and power: A conversation between Michel Foucault and Gilles Deleuze. In: Foucault M, editor. Language, counter-memory, practice: Selected essays and interviews, France; 1977. p. 205-217.

4. Signorini I. Epistemologias da pesquisa no campo aplicado dos estudos da língua (gem). DELTA. 2015;31.

5. Pinheiro PA. Práticas colaborativas de escrita via Internet: repensando a produção textual na escola. Eduel. Brazil; 2013.

6. Petrilson AP. A era do 'multissinóptico': que (novos) letramentos estão em jogo? Educação em Revista. 2014;30(2):137-160.

7. Pinheiro PA, Felicio RP. Copiar-colar e remix: o que a escola tem a ver com isso? Calidoscopio. 2016;14(1):59-69.

8. Pinheiro PA, Gomes C. Multi/novos letramentos em ambiente digital: uma análise do Google Search Education. Revista do GEL. 2015;12(1):109-138

9. Pinheiro PA, Ricarte LT. O uso do software Scratch na escola pública: discussão da noção de autoria e remixagem na contemporaneidade. Edição atual Anais do SIELP. 2014;3.

10. Søby M. Digital competence from education policy to pedagogy: the Norwegian context. In: Lankshear C, Knobel M, editors. Digital Literacies. Peter Lank, USA; 2008. p. 119-150.

11. Knobel M, Lankshear C. A new literacies sampler. Peter Lang Publishing Inc, Switzerland; 2007. p. 249.

12. Lévy P. A conexão planetária: o mercado, o ciberespaço, a consciência. Geografia Londrina. 2001;12(2):189.

13. Prensky M. Digital Natives, Digital Immigrants. On the Horizon 2001;9(5):1-5.

14. Gee JP. Social linguistics and literacies: ideology in discourses, 2nd ed.Taylor \& Francis, London; 1996. p. 218.

15. Cervetti G, Pardales MJ, Damico JS. A tale of differences: comparing the traditions, perspectives and educational goals of critical reading and critical literacy. Reading Online. 2001;4(9).

16. Freire P. Education as the practice of freedom. In: Ramos MB, editor. Education for critical consciousness. The Continuum Publishing Company, USA; 1982. p. 1-84.

17. Luke A. Foreward. Critical literacy: enhancing students' comprehension of text. In: McLaughlin M, Devoogd G, editors. Scholastic, USA; 2004. 
18. Reilly OT. What is Web 2.0? Design patterns and business models for the next generation of software. 2005 .
19. Silva KA, Santos LIS, Justina OD. Entrevista com Kanavillil Rajagopalan: ponderações sobre linguística aplicada, política linguística e ensinoaprendizagem. Revista de Letras Norte@mentos. 2011;4(8):75-81. 